\title{
ANÁLISIS DEL CONSENTIMIENTO DEL PROGENITOR AL DESPLAZAMIENTO O LA RETENCIÓN DEL MENOR EN UN ESTADO DISTINTO AL DE SU RESIDENCIA HABITUAL. SU INTERPRETACIÓN EN EL AUTO DE LA AUDIENCIA PROVINCIAL BARCELONA (SECCIÓN 18 ${ }^{\mathrm{a}}$ ) DE 27 DE NOVIEMBRE
}

\author{
ANALYSIS OF THE CONSENT OF THE NON- ABDUCTING \\ PARENT TO THE REMOVAL OR RETENTION OF THE CHILD. \\ INTERPRETATION OF THE SPANISH COURT OF APPEAL \\ OF BARCELONA (SECCION 18 ${ }^{\mathrm{a}}$ ) OF $27^{\mathrm{TH}}$ NOVEMBER
}

\author{
Mónica Herranz Ballesteros \\ Profesora Titular de DIPr de la UNED \\ ORCID ID: 0000-0002-0748-6598
}

Recibido: 18.06.2019 / Aceptado: 11.07.2019

DOI: https://doi.org/10.20318/cdt.2019.4984

Resumen: Desplazamiento de un menor desde Corea a España. Aplicación del artículo 13 a) del Convenio de La Haya de 1980. Consentimiento del progenitor al traslado del menor. Retención lícita en España

Palabras clave: sustracción internacional de menores, Convenio de La Haya de 1980, consentimiento de traslado, retención lícita.

Abstract: International Child Abduction from Corea to Spain. Application of article 13 a) of the Hague Convenion on Civil Aspects of International Child Abduction of 1980. Father's permission. Non wrongful retention.

Keywords: international child abduction, Hague Convention on the Civil Aspects of International Child Abduction of 1980, father's permission to removal of the child, non wrongful retention.

Sumario: I. Introducción. II. Hechos. III. Razonamientos jurídicos que suscita el auto de la AP de Barcelona. 1. Aplicación del CLH de 1980. A) Ámbito de aplicación espacial del CLH de 1980. B) Ámbito de aplicación personal del CLH de 1980. 2. Calificación del supuesto de conformidad con el CLH de 1980. 3. El consentimiento al desplazamiento como elemento decisivo en torno a la licitud o ilicitud del traslado o retención del menor. A) Ilicitud del traslado o retención: consentimiento al desplazamiento del menor con alcance temporal limitado. B) Licitud del traslado o retención del menor: consentimiento o aquiescencia al desplazamiento o retención del menor. 4 . La interpretación del consentimiento al traslado por la AP de Barcelona en el auto de 27 de noviembre de 2018. IV. A modo de conclusión.

\footnotetext{
*El presente trabajo se adscribe al Proyecto de I+D DER2017-86017-R, "Obstáculos a la movilidad de personas en los nuevos escenarios de la UE", concedido por el Ministerio de Economía, Industria y Competitividad, en los términos del artículo 37 de la Ley 14/2011, de 1 de junio, de la Ciencia, la Tecnología y la Innovación (BOE n 131, 2-VI-2011).
} 


\section{Introducción}

1. El 27 de noviembre de 2018 la Audiencia Provincial de Barcelona (Sección $18^{\mathrm{a}}$ ) desestima el recurso de apelación presentado contra la decisión dictada por el Juzgado de Primera Instancia $\mathrm{n}^{\circ} 16 \mathrm{de}$ Barcelona (Familia) por el que se denegó la restitución de un menor a Corea del Sur ${ }^{1}$. En el supuesto se cuestionaba la licitud o ilicitud de la retención del menor en España por su progenitora.

2. A continuación, en el presente trabajo se describen más detenidamente cuáles son los hechos que dan lugar a la situación litigiosa (II). Se extraerán los razonamientos jurídicos que plantea la decisión (III): de un lado, la aplicación del Convenio de 25 de octubre de 1980 sobre los Aspectos Civiles de la Sustracción Internacional de Menores (en adelante Convenio de La Haya de 1980 o CHL de 1980), analizando los ámbitos de aplicación del instrumento convencional (1); de otro lado, la calificación del supuesto conforme al CLH de 1980 (2); posteriormente se estudiará, en primer lugar, el consentimiento al desplazamiento como elemento decisivo en torno a la licitud o ilicitud del traslado o retención del menor (3); en segundo lugar, de forma concreta, la interpretación del consentimiento al traslado otorgado por la AP de Barcelona en el auto de 27 de noviembre de 2018 (4); finalizará el trabajo con unas conclusiones sobre el asunto (IV).

\section{Hechos}

3. La Sra. Sara y el Sr. Vicente contraen matrimonio en Corea donde nace su hijo y donde posteriormente es escolarizado ${ }^{2}$. En marzo de 2017, la progenitora, en compañía del menor, decide venir a España a visitar a su familia y en particular a un familiar que estaba enfermo. El progenitor, tal y como se recoge en el Fundamento Jurídico tercero de la decisión de la AP, estuvo conforme con dicho viaje e incluso viajó a España para visitarlos en el mes de julio. Aunque en un principio, conforme se refleja en la decisión, se esperaba que el traslado de Sra. Sara y el niño fuera por un tiempo determinado, posteriormente ésta decide retrasar su regreso a Corea y, en septiembre del mismo año, comunica al Sr. Vicente su intención de permanecer junto con el menor en España.

Después de que la madre pusiera en conocimiento del progenitor su deseo de quedarse en España, éste muestra a la progenitora su intención de enviar la documentación que precise para que ella gestione en la Embajada de Corea en España lo que sea necesario para de forma textual: “(...) hacer legal al hijo en España (...)".

Sin embargo, a continuación, el Sr. D. Vicente plantea ante los Tribunales españoles una demanda de restitución del menor a Corea al considerar que, si bien ha sido trasladado a España con su consentimiento inicial, es retenido posteriormente en este país por la demandada, sin su consentimiento, por tanto, de forma ilícita ${ }^{3}$.

4. El Juzgado de Primera Instancia $\mathrm{n}^{\mathrm{o}} 16$ de Barcelona (Familia) desestima, mediante auto dictado el 8 de agosto de 2018, la demanda interpuesta por el Sr. Vicente acordando la no ilicitud de la retención del menor Juan Ramón.

El Sr. D. Vicente a la vista de la resolución dictada en Instancia, presenta recurso de apelación el 21 de septiembre de 2018 ante la AP de Barcelona. La Audiencia dicta un auto seis días más tarde -el 27 de noviembre de 2018-, en el que desestima el recurso al confirmar la decisión dictada por el Juzgador de Primera Instancia y, en consecuencia, declara la no ilicitud de la retención del menor en España.

\footnotetext{
${ }^{1}$ ECLI: ECLI:ES:APB:2018:7912A

2 Aunque en la decisión no se dice de forma expresa por los datos que se presentan parece ser un matrimonio mixto entre una nacional española y un nacional coreano. Ambos deciden instalar su residencia habitual en Corea

${ }^{3}$ De conformidad con el procedimiento establecido del artículo 778 bis al 778 quáter de la LEC 1/2000.
} 


\section{Razonamientos jurídicos que suscita el auto de la AP de Barcelona}

\section{Aplicación del CLH de 1980}

6. La aplicación del CLH de 1980 a un supuesto de sustracción internacional de menores está condicionada al cumplimiento de: A) los Estados implicados en el supuesto -Estado donde el menor tiene su residencia habitual y el Estado al que el menor ha sido trasladado o donde es retenido- han de ser ambos Estados parte del Convenio; por tanto, el supuesto tiene que estar en el ámbito de aplicación espacial cubierto por el instrumento convencional; B) además, es necesario que el supuesto planteado esté incluido en el ámbito personal del CLH de 1980.

\section{A) Ámbito de aplicación espacial del CLH de 1980}

7. El CLH de 1980 es un texto que se aplica inter partes ${ }^{4}$; en consecuencia, los Estados implicados esto es, el Estado desde donde el menor es trasladado y el Estado al que el menor es desplazado, han de ser Estados parte del CLH de 1980. Efectivamente en el caso resuelto por la AP tanto España, desde el uno de octubre de 1987, como Corea del Sur desde uno de marzo de 2013 son parte del CLH de 1980.

Hay que advertir que además conforme a lo establecido en la normativa de fuente interna española el proceso de restitución establecido en los artículos 778 bis al 778 quáter de la LEC 1/2000 solo va a ser aplicable cuando el menor haya sido desplazado desde otro Estado de la Unión Europea o de un Estado que sea parte de un convenio internacional ${ }^{5}$. En consecuencia, que el menor provenga de un Estado, en este caso, parte del CLH de 1980 cumpliría con la condición de aplicación de la norma.

8. Ahora bien la posición que en la Conferencia de La Haya tienen España y Corea no es la misma. Así, mientras España tiene la condición de Estado miembro de la Conferencia de La Haya de Derecho Internacional Privado no sucede lo mismo con Corea del Sur. Situación que tiene su reflejo en los distintos textos convencionales.

En relación al CLH de 1980 y según lo previsto en su artículo 37: "El Convenio estará abierto a la firma de los Estados que eran Miembros de la Conferencia de La Haya de Derecho Internacional Privado en el momento de su Decimocuarta Sesión". En caso de Estados que no son miembros de la Conferencia de La Haya - como Corea- también pueden suscribir el Convenio si bien su efectividad y aplicación entre los Estados está condicionada (se trata de un Convenio semi-cerrado).

9. De acuerdo con el artículo 38 del CLH de 1980 cualquier Estado que no sea miembro de la Conferencia de La Haya pueda adherirse al Convenio, si bien para que ésta tenga efectos, y por tanto el Convenio sea aplicable, entre el Estado adherido y los Estados contratantes estos últimos tendrán que realizar una declaración de aceptación expresa sobre la adhesión ${ }^{6}$.

10. La aceptación por los Estados miembros de la Unión Europea a las adhesiones de terceros Estados al CLH de 1980 fue objeto de polémica en el ámbito de la Unión. La controversia se centró en torno a quién era el titular para la aceptación de la adhesión al CLH de 1980 de terceros Estados, bien los Estados miembros bien la Unión Europea. Cuestión que fue sometida por la Comisión al TJUE, quien emitió el Dictamen 1/13 el 14 de octubre de 20147.

\footnotetext{
${ }^{4}$ En mayo de 2019 son cien los Estados parte del CLH de 1980. Puede consultarse en www.hcch.com

${ }^{5}$ Artículo 778 bis: "En los supuestos en que, siendo aplicables un convenio internacional o las disposiciones de la Unión Europea, se pretenda la restitución de un menor o su retorno al lugar de procedencia por haber sido objeto de un traslado o retención ilícito y se encuentre en España, se procederá de acuerdo con lo previsto en este Capítulo. No será de aplicación a los supuestos en los que el menor procediera de un Estado que no forma parte de la Unión Europea ni sea parte de algún convenio internacional".

${ }^{6}$ En relación a la valoración de este sistema véase E. PÉrez VERA, "Sustracción internacional de menores. Aspectos civiles”, BIMJ Año LIV, suplemento al núm., 1865, de 15 de marzo de 2000, pp. 50-51.

${ }^{7}$ ECLI:EU:C:2014:2303
} 
En el mismo el TJ estableció que las declaraciones de aceptación a la adhesión a tal texto están incluidas en las competencias externas de la Unión ${ }^{8}$. De forma que los Estados miembros no podrán hacer declaraciones unilaterales de aceptación a las adhesiones de terceros Estados al CLH de 1980. Se pretende con ello conseguir la homogeneidad en la aplicación territorial del texto, evitando, en palabras del TJUE, "menoscabar la aplicación uniforme y coherente del Reglamento 2001/2003 y, en particular, de las normas de cooperación entre las autoridades de los Estados miembros cada vez que una situación de sustracción internacional de un menor afectara a un Estado tercero y a dos Estados miembros, uno de los cuales hubiera aceptado la adhesión de ese Estado tercero a dicho Convenio y el otro no".

Tras la adhesión de Corea al CLH de 1980, se publicó una Decisión del Consejo por la que se autorizó a los Estados miembros que aún no lo hubieran hecho realizar la declaración de aceptación a la adhesión de Corea al CHL de 1980 en interés de la Unión Europea ${ }^{10}$. Conforme a la citada Decisión España realiza la declaración de aceptación de Corea a la adhesión del CLH de 1980 el 7 de febrero de 2017. El Convenio está en vigor entre ambos Estados desde el 1 de mayo de $2017^{11}$.

11. En consecuencia, y aunque no se indica exactamente cuándo se inicia el procedimiento de restitución ante el Juzgado de Primera Instancia parece que la demanda ante el mismo se plantea cuando el texto está ya en vigor entre ambos Estados (cumpliendo también el ámbito temporal de aplicación del texto).

\section{B) Ámbito de aplicación personal del CLH de 1980}

12. De conformidad con el artículo 4 del CLH de 1980 este texto limita su aplicación: a todo menor que haya tenido su residencia habitual inmediatamente antes de la infracción de los derechos de custodia o de visita en el territorio de un Estado contratante y sea trasladado al territorio de un segundo Estado contratante. Dejándose de aplicar cuando el menor alcance los dieciséis años.

Ninguno de los elementos a los que el texto condiciona su aplicación suscitan problema en el caso resuelto por la AP de Barcelona.

13. En relación al lugar de residencia habitual del menor. La determinación del lugar de residencia habitual del menor es uno de los elementos que más controversia plantea en supuestos de sustracción internacional de menores ${ }^{12}$. Su ubicación en un Estado - del que fue desplazado- o en otro - en el territorio del Estado al que fue desplazado- supone, en definitiva, que haya habido o no traslado ilícito del menor.

En el caso objeto de análisis no se discute por las partes que la residencia habitual inmediatamente anterior al traslado del menor estaba situada en otro Estado contratante del CHL de 1980. En relación a este aspecto al Audiencia establece en el Fundamento jurídico tercero: "La resolución apelada

\footnotetext{
${ }^{8}$ Sobre el mismo puede verse entre otros, A. Borras RodríGuez, "La aceptación de las adhesiones al Convenio de La Haya de 1980 sobre sustracción de menores. El Dictamen 1/13 de 14 de octubre de 2014”, La Ley UE, mes 21, 2014, pp. 42-50; C. CARrillo Lerma, "Competencia externa exclusiva de la Unión Europea y Derecho Internacional Privado", CDT, (Marzo 2015), Vol. 7, No 1, pp. 46-55; P. Beaumont, "A Critical Analysis of the Judicial Activism of the Court of Justice of the European Union in Opinion 1/13". P. Franzina (Ed.), The External Action of the EU in the Field of Private International Law after Opinion 1/13.pp. 55-74.

9 Punto 89 Dictamen $1 / 13$ del TJUE.

${ }^{10}$ Decisión (UE) 2016/2313 del Consejo de 8 de diciembre de 2016 por la se autoriza a determinados Estados miembros a aceptar, en interés de la Unión Europea, la adhesión de la República de Corea al Convenio de La Haya de 1980 sobre los aspectos civiles de la sustracción internacional de menores. DO de 20/12/2016 Serie L 345/59.

Los siguientes Estados miembros de la Unión Europea habían aceptado la adhesión de Corea al CLH de 1980 antes del Dictamen 1/13 del TJUE y de la Decisión del Consejo: Lituania (2013); República Checa (2013); Irlanda (2013).

${ }^{11}$ De conformidad con lo establecido en el artículo 38.5 del CLH de 1980.

Puede consultarse en: https://wwcch.net/es/instruments/conventions/status-table/acceptances/?mid=1204

${ }_{12}$ Prueba de ello es por ejemplo la abundante jurisprudencia que sobre este aspecto ha tratado no solo a nivel nacional sino en el caso de sustracciones entre Estados miembros por el TJUE. Un estudio sobre la misma en: I. ReIg FabAdo, "La construcción del concepto autónomo de residencia habitual del menor en los supuestos de sustracción internacional de menores", $C D T$, (Marzo 2019) Vol. 11, Núm., 1, pp. 877-888. L.A. Pérez Martín, "Determinación y trascendencia de la residencia habitual en las crisis familiares internacionales", Crisis matrimoniales internacionales y sus efectos: derecho español y de la Unión Europea. Estudio normativo y jurisprudencial, (dir. M. Guzmán y M. Herranz), Edt. Tirant lo Blanch, 2018, pp. 927-964.
} 
ha declarado probado que la residencia habitual del hijo menor de las partes era Corea del Sur, criterio con el que esta Sala coincide, pues ambas partes reconocen que en aquel país se casaron, allí nació Juan Ramón y allí estaba escolarizado".

14. En relación a los menores a los que el texto es aplicable serán aquellos que aún no hayan cumplido los dieciséis años y ello con independencia de que la mayoría de edad, conforme a la ley que resultara aplicable, se alcance una vez cumplidos los dieciocho años. Desde luego el texto reduce el número de menores que considera protegibles; ahora bien, la edad establecida como límite para la aplicación del texto -dieciséis años- es muy razonable teniendo en cuenta la materia y objetivos del CLH de 1980. Como explica E. Pérez Vera en el Informe Explicativo al Convenio una persona de más dieciséis años tiene por lo general una voluntad propia que es difícil ignorar, ya sea por uno o por otro progenitor, ya sea por una autoridad judicial o administrativa ${ }^{13}$.

No parece que el asunto resuelto por la Audiencia Provincial planteara controversia sobre este aspecto. Aunque en ningún momento se ofrece el dato de la edad del menor por el órgano judicial, no parece que sea éste un impedimento a la aplicación del CLH de 1980 ni en el momento de la acción ni en el de la resolución ${ }^{14}$; por tanto, el menor Juan Ramón debe en todo caso ser menor de dieciséis años tanto en el momento en el que el litigio se plantea ante el Juzgado de Primera Instancia como cuando la Audiencia resuelve.

Sobre este aspecto de manera expresa la Fiscalía General del Estado en la Circular 6/2015 de la Fiscalía, sobre los aspectos civiles de la sustracción internacional de menores se establece en el criterio de actuación décimo: "Los Fiscales deberán partir de que si el menor afectado cumple los dieciséis años durante la tramitación del procedimiento no procederá adoptar resolución alguna sobre su retorno o restitución".

\section{Calificación del supuesto de conformidad con el CLH de 1980}

15. El artículo 3 del CLH de 1980 define cuando el desplazamiento o retención de un menor se considera ilícito $^{15}$. Es conocido que el objeto primordial del CLH de 1980 es la restitución inmediata del menor al Estado de su residencia habitual salvo que concurra alguna de las excepciones que contempla el texto.

16. En el caso resuelto la AP de Barcelona se centró en determinar si se había producido o no la segunda de las excepciones al retorno incluidas en la letra a) del artículo 13 y alegada por la progenitora. Excepción, que conforme a la decisión del Juzgado de Primera Instancia, había concurrido en este supuesto y, en consecuencia, la retención no se consideraba ilícita.

Artículo 13 letra a): "No obstante lo dispuesto en el artículo precedente, la autoridad judicial o administrativa del Estado requerido no está obligada a ordenar la restitución del menor si la persona, institución u otro organismo que se opone a su restitución demuestra que: $a$ ) la persona, institución u organismo que se hubiera hecho cargo de la persona del menor no ejercía de modo efectivo el derecho de custodia en el momento en que fue trasladado o retenido o había consentido o posteriormente aceptado el traslado o retención".

Las excepciones al retorno previstas en este apartado tienen que ver con la conducta del progenitor que se ve desposeído de la compañía del menor y demanda su restitución. En consecuencia, es su comportamiento el que determina si la acción de quien trasladó al menor pasa de ilícita a lícita. Su com-

\footnotetext{
13 E. Pérez Vera, “Sustracción internacional de menores...”, op. cit., pp. 63-64.

${ }^{14} \mathrm{Ibid}$., "no se podrá llevar a cabo o aprobar ninguna acción o resolución respecto a un menor tras su decimosexto cumpleaños", p. 64.

${ }^{15}$ El artículo 3 del CLH de 1980 establece: "El traslado o la retención de un menor se considerarán ilícitos: a) cuando se hayan producido con infracción de un derecho de custodia atribuido, separada o conjuntamente, a una persona, a una institución, o a cualquier otro organismo, con arreglo al Derecho vigente en el Estado en que el menor tenía su residencia habitual inmediatamente antes de su traslado o retención; y b) cuando este derecho se ejercía de forma efectiva, separada o conjuntamente, en el momento del traslado o de la retención, o se habría ejercido de no haberse producido dicho traslado o retención".
} 
portamiento puede proyectarse en dos momentos distintos en relación a la excepción: cuando autoriza el traslado con lo cual se produce consentimiento; posteriormente, si acepta la situación ${ }^{16}$.

\section{El consentimiento al desplazamiento como elemento decisivo en torno a la licitud o ilicitud del traslado o retención del menor}

17. El elemento central en la aplicación del artículo 13 en su letra a) es el comportamiento del progenitor que se ve desposeído de la compañía del menor.

18. Un repaso por la jurisprudencia española permite comprobar que, aunque existe una abundante práctica en torno a la excepción del artículo 13 a), su alegación por quien ha trasladado al menor suele producirse de forma conjunta con otras excepciones en las que sustentar la permanencia del menor en el Estado al que ha sido trasladado. En efecto, generalmente, junto al consentimiento o aquiescencia del progenitor que ahora denuncia la ilicitud del traslado, quien se opone a la restitución añade, en defensa de la permanencia del menor al Estado que fue trasladado, otras excepciones con el fin de fundamentar la denegación del retorno ${ }^{17}$.

19. Como sucede en las demás excepciones a la devolución del menor contenidas en el CLH de 1980, quien alega la concurrencia de cualquier de ellas y entre estas el consentimiento al desplazamiento por parte del otro progenitor tiene que demostrarla; por tanto, no es el progenitor desposeído quien tiene que probar la ausencia de consentimiento al traslado.

Lo expone de forma muy clara respecto de la aplicación de la excepción de la letra a) del artículo 13 la AP de Las Palmas (Sección 3ª en Auto núm., 69/2009 de 10 de marzo ${ }^{18:}$ : Era la demandada la que tenía que acreditar, y no como parece señalar la sentencia de instancia, la existencia del consentimiento, no ya por cuanto la prueba de un hecho negativo se torna en diabólica sino porque es ella la que alega un hecho al que debe anudarse consecuencias jurídicas y además por su facilidad probatoria”.

\section{A) Ilicitud del traslado o retención: consentimiento al desplazamiento del menor con alcance tem- poral limitado}

20. Es habitual que se produzcan supuestos en los que en principio uno de los progenitores consiente el traslado del menor al segundo Estado con el otro progenitor, pero este consentimiento se otorga con un alcance temporal limitado por lo que posteriormente se denuncia la ilicitud del traslado o retención del menor. Si esto último es así supone que el traslado o retención que, en principio, es lícito se vuelve ilícito.

Hay que aclarar que en estos asuntos no se trata de supuestos en los que la estancia del menor en el segundo Estado se debe al posible disfrute del derecho de visita concedido a uno de los progenitores cuyo ejercicio se permite realizar fuera del Estado de la residencia habitual del menor por un plazo determinado. Son supuestos en los que el permiso de uno de los progenitores se otorga para que el menor se traslade con el otro, generalmente a su país de origen, con el propósito, por ejemplo, de realizar visitas a familiares. En este segundo Estado ninguna de las partes tiene establecida la residencia habitual, tampoco el progenitor que desplaza al menor.

21. A continuación, se exponen algunos ejemplos sobre esta situación:

La AP de Las Palmas (Sección 3 ${ }^{\mathrm{a}}$ ) por auto dictado el 10 de marzo de $2009^{19}$, revoca la decisión dictada en Primera Instancia en la que se denegaba la restitución solicita dando por probado la existencia

${ }^{16}$ Véase al respecto la Circular de la Fiscalía 60/2015 sobre aspectos civiles de la sustracción internacional de menores. pp. 34-35.

${ }_{17}$ Sin embargo, en el caso de la AP de Barcelona (Sección 18) de 27 de noviembre, objeto de este estudio, no se alega ninguna excepción más en la que fundamentar la denegación del retorno del menor.

${ }^{18}$ AC2009/1326.

19 AC 2009/1326. 
de acuerdo por parte del progenitor sobre el desplazamiento desde Italia a España de las dos menores y, por tanto, considerando lícita su retención. Sin embargo, la AP establece: "El recurso, tanto el de la abogacía del estado como el interpuesto por el padre deben prosperar y ello por cuanto la premisa mayor, esto es el consentimiento del traslado de residencia por parte del padre de las hijas a España no ha sido mínimamente acreditado. Las únicas pruebas de la existencia de dicho consentimiento están en lo que ha manifestado la madre y la hermana de ésta en el acto del juicio y dichas manifestaciones sin otras pruebas que lo corroboren no pueden acreditar la existencia del consentimiento negado por la otra parte, y la testifical escaso, o nulo valor, tiene pues, aparte de que la referida testigo manifestó que su interés era que su hermana ganara el pleito, ella declaró que tenía conocimiento del hecho de la existencia del consentimiento no por razón directa sino por referencia ya que así se lo había dicho su hermana), las demás pruebas obrante en las actuaciones, esto es las documentales, ninguna luz arrojan al asunto en lo relativo a que el padre consintió en el traslado de la residencia" ${ }^{20}$.

La AP de Madrid (Sección 22a) en auto de 31 de marzo de 2015²1, resuelve un supuesto en el que la demandada alega junto con la excepción del artículo 13 letra a) la aplicación de la excepción contenida en el artículo 13 b) del CLH de 1980. Respecto de la primera de las excepciones el órgano judicial establece que: "el consentimiento del padre al viaje de la niña a España junto con su madre como un acto propio del recurrente no puede, objetivamente, generar la confianza de un aquietamiento del padre al traslado definitivo de la niña a este país, pues, aquel comportamiento puntual y realizado, con ocasión de aquel conflicto - y período vacacional - no puede tener la proyección y vinculación que se pretende, como lo evidencia, en primer lugar, la redacción genérica del documento policial al que se ha hecho referencia y, en segundo lugar, la inmediata puesta en marcha por parte del padre, de cuantos procedimientos judiciales estuvieron a su alcance para lograr el regreso de Estela a su residencia habitual"22.

Resulta muy interesante el auto de la AP de Las Palmas (Sección $3^{a}$ ) de 21 de junio de $2017^{23}$. El caso trató sobre un menor con residencia en Reino Unido donde se otorgó la guarda compartida a ambos progenitores. El progenitor desplaza al menor a Las Palmas y allí lo retiene sin que se produzca su retorno a Reino Unido. La madre interpone solicitud de restitución y ante la misma el demandado argumentan entre otros aspectos: 1) consentimiento de la progenitora al traslado del menor y 2) la pasividad de la progenitora en relación a la permanencia del menor en España. Pues bien, en relación al primer argumento la AP estima que no hay en realidad verdadero consentimiento de la madre quien no consintió el cambio de residencia ni procedió al cambio judicial de la residencia habitual del menor ${ }^{24}$; y en referencia al segundo la Audiencia afirma que la madre sale de dicha situación de pasividad de la situación cuando se le comunica por parte de los Servicios Sociales la situación de abandono en la que se encuentra el menor.

De forma tajante la Audiencia establece: "Por todo lo expuesto, lo único que se constata es una retención ilícita del menor no amparada por resolución judicial, que ha contrariado el permiso de viaje que finalizaba en enero de 2016, y una situación de tolerancia de la madre hasta noviembre de 2016, en que ya presenta denuncias en España sobre la situación de su hijo, todo lo cual no cabe confundir con una aceptación formal del cambio de residencia de su hijo, a los efectos de aplicar el art. 13 del Convenio, lo que hubiera entrañado evidentemente una pérdida de su custodia, en lo que tampoco ha estado nunca conforme" 25 .

La AP de Santa Cruz de Tenerife (Sección $1^{\mathrm{a}}$ ) por auto dictado el 10 de mayo de $2018^{26}$, resuelve sobre la sustracción de dos menores desde Italia a España por el progenitor quien alega, además de la

\footnotetext{
${ }^{20}$ Fundamento Jurídico Primero.

${ }^{21} \mathrm{JUR} / 2015 / 117498$.

${ }^{22}$ Fundamento Jurídico Quinto.

${ }^{23}$ ECLI: ECLI:ES:APGC:2017:977

${ }^{24} \mathrm{La}$ AP en su F Jo Tercero establece: "De la prueba aportada a los autos, las comunicaciones de mensajería cursada entre apelante y apelada, y los interrogatorios de las partes, lo que resulta no es un verdadero consentimiento y aceptación de la madre al cambio de residencia, sino una mera situación de pasiva tolerancia a esa situación de hecho producida cuando el menor no regresa a Londres en febrero de 2016. No hay constancia documental de ningún acuerdo entre los padres para que, contrariando lo dispuesto en la autorización de salida al extranjero, fijar la residencia permanente del niño en Las Palmas".

${ }^{25} \mathrm{~F}^{\mathrm{o}} \mathrm{J}^{\mathrm{o}}$ Tercero.

${ }^{26}$ AC 2018/1294.
} 
concurrencia de la excepción contenida en la letra b) del artículo 13 del CLH de 1980, la existencia de consentimiento materno a dicho traslado. Ante esta situación la AP establece: "entrando en el requisito que se ha cuestionado en esta alzada, no se ha quedado acreditado que haya existido consentimiento prestado por la madre; obra al folio 170 de autos una copia de una nota manuscrita en la que se refiere que la madre autoriza a que los menores se empadronen en Tenerife con el padre, pero no se constata ni su fecha ni su autenticidad y que no se compadece con que en el mes de octubre de 2017 la madre ya denunciare la sustracción de sus hijos".

22. Los casos descritos son supuestos que responden a traslados lícitos para los que, posteriormente, la retención del menor en el territorio del Estados al que fueron desplazados se considera ilícita. En todos ellos se demuestra que el consentimiento del progenitor no se da a un traslado permanente, sino con un alcance limitado en el tiempo. En cualquier caso, compartimos la reflexión de la AP de Las Palmas (Sección 3 $3^{\mathrm{a}}$ ) de 21 de junio de 2017 ya citado cuando en relación a esta excepción afirma: "Ciertamente ésta es la excepción legal a la aplicación de la restitución del menor de perfiles más dudosos", lo que de muestra la dificultad que conlleva su correcta interpretación y aplicación por parte de la autoridad judicial.

\section{B) Licitud del traslado o retención del menor: consentimiento o aquiescencia al desplazamiento o retención del menor}

23. El trasladado del menor a fin de que permanezca en otro Estado con el consentimiento de ambos progenitores conllevará la modificación de su residencia habitual y, en consecuencia, el cambio de las autoridades que serán competentes en su caso para decidir las cuestiones relativas al menor.

Cuando el traslado del domicilio se produce con el acuerdo de ambos progenitores, la decisión parece adoptarse en un contexto en el que no hay crisis familiar y, por tanto, son asuntos que no plantean controversia jurídica. Son las situaciones de crisis familiar las que, sin duda, suscitan los problemas más importantes cuando se trata de decidir uno de los elementos más importantes en la vida de un menor: el lugar de su domicilio y, sobre todo, cuando supone determinar si éste ha de situarse en un Estado, a veces muy alejado, en todos los sentidos, de aquel en el que tiene su residencia habitual.

24. Pues bien, el traslado del menor con el propósito de trasladar su domicilio es un aspecto que conforme al derecho español pertenece al ámbito de facultades contenidas en el ejercicio de la patria potestad; en consecuencia, corresponde a ambos progenitores adoptar de común acuerdo una decisión al respecto ${ }^{27}$. Cuando los progenitores no llegan a un acuerdo tendrán que recurrir al juez para que decida siempre en interés del menor. Estos supuestos plantean casos de reubicación internacional de menores. Situaciones en las que el progenitor que pretende trasladarse a otro Estado quiere hacerlo con el menor para lo que tiene que solicitar el permiso del otro progenitor, y en caso de no obtenerlo recurrir al órgano judicial para que decida en torno a la autorización o no del desplazamiento del menor ${ }^{28}$.

25. El marco de este trabajo está configurado por los supuestos en los que el progenitor "sustractor" alega que existe acuerdo entre ambos progenitores al traslado del menor y, en consecuencia, no se ha solicitado permiso al órgano judicial para proceder al desplazamiento. Ahora bien, posteriormente la existencia del acuerdo alegado por un progenitor se niega por el otro desde el momento en el que éste último, es decir aquel con quien el menor no se trasladó, decide iniciar un proceso para su restitución.

${ }^{27}$ Establece el artículo $156 \mathrm{del} \mathrm{Cc:} \mathrm{"La} \mathrm{patria} \mathrm{potestad} \mathrm{se} \mathrm{ejercerá} \mathrm{conjuntamente} \mathrm{por} \mathrm{ambos} \mathrm{progenitores} \mathrm{o} \mathrm{por} \mathrm{uno} \mathrm{solo}$ con el consentimiento expreso o tácito del otro. En caso de desacuerdo, cualquiera de los dos podrá acudir al Juez quien, después de oír a ambos y al hijo si tuviera suficiente juicio y, en todo caso, si fuera mayor de doce años, atribuirá sin ulterior recurso la facultad de decidir al padre o la madre".

${ }^{28}$ En la doctrina española no ha sido un tema muy estudiado. Entre los trabajos pueden verse los de: C. GonZÁlez BeILfusS, "El traslado lícito de menores: las denominadas Relocation Disputes", REDI, (2010), 2, pp. 52-75; E. Rodríguez PINAU, "Revisión de la atribución de la custodia y la reubicación internacional del menor en interés superior del menor: Comentario a la STS de 18 de enero 2017 (RJ 2017, 343), Cuadernos Cívitas de Jurisprudencia Civil, enero-abril 2018, pp. 9-21. 
26. A continuación, se analizan supuestos para los que las autoridades estiman que sí ha habido consentimiento al traslado del menor y, por tanto, la excepción del artículo 13 letra a) se aplica considerando entonces que no hay sustracción o retención ilícita del menor o menores en España:

La AP de Baleares (Sección $3^{a}$ ), en auto dictado el 13 de marzo de $2003^{29}$, establece la licitud del traslado del menor desde Argentina a España desestimando con ello el recurso interpuesto por el Abogado del Estado ante el Auto dictado por el Juzgado de Primera Instancia núm., 3 de Palma. En relación a la aplicación de la excepción del artículo 13 letra a) del CLH de 1980 el Tribunal establece que la autorización del padre no era solo una autorización de viaje sino de permanencia de diez años en España. De manera expresa el Tribunal afirma: "En el caso no se da traslado ilícito por parte de la madre del menor Germán desde Argentina a esta ciudad de Palma ya que, siendo ciertamente la patria potestad compartida, el padre dio su consentimiento para su salida al extranjero en compañía de su madre por un lapso de 10 años, lo que supone autorizar no sólo la salida, como afirma el recurrente, sino también la residencia fuera de su país de origen, faltando el padre a la verdad al formular ante la Autoridad Central Argentina la petición de restitución al afirmar que su hijo fue secuestrado por la madre y trasladado a España, falta de ilicitud del traslado del menor conforme al artículo 3 del Convenio que impide su restitución sin necesidad de entrar a examinar si, además, concurren las circunstancias previstas en el Convenio y Ley de Enjuiciamiento Civil para denegar la restitución ante un traslado ilícito" ${ }^{30}$.

La AP de Madrid (Sección 24a ), en auto de 25 de abril de 2012, establece que no se ha producido sustracción ilícita del menor dado que, entre otros aspectos, la Audiencia considera que se ha demostrado el consentimiento del padre al traslado del menor a España ${ }^{31}$. El Tribunal argumenta: "Su traslado a Madrid tres meses antes parto, el nacimiento del menor en Madrid en donde está empadronado, las largas ausencias del padre que acudió a conocer al hijo transcurridos 16 días tras su nacimiento, habiendo permanecido largas temporadas madre e hijo en Madrid, tal y como se refleja en la cartilla de asistencia sanitaria del menor y ello con anterioridad a julio de 2010 , fecha en la que $\mathrm{D}^{\mathrm{a}}$ Reyes prorroga su estancia con su hijo con el consentimiento inicial paterno, si bien tras su no retorno a Praga, el padre interesó el presente procedimiento" 32 .

La AP de Granada (Sección 5a), en auto de 8 de septiembre de 2017, desestima el recurso de apelación presentado por el progenitor frente a la decisión en Instancia que establecía la falta de competencia de las autoridades españolas para adoptar medidas de protección sobre un menor, dado que la competencia la ostentan las autoridades ecuatorianas donde el menor tiene su residencia habitual ${ }^{33}$. Frente a esta decisión el progenitor alega que el desplazamiento del menor fue realizado sin su consentimiento y que, por tanto, en aplicación del artículo 7 del CLH de 1996 dicho traslado es ilícito.

La AP establece dos elementos en su razonamiento: la existencia de consentimiento del apelante que se ve reforzado aún más con la aceptación de la situación creada; así como su desidia en torno a su falta de actuación en la interposición de la demanda de restitución ante las autoridades españolas. Respecto de la primera alegación: la prueba reside en las visitas realizas de forma pacífica por parte del progenitor al menor en Ecuador en tres ocasiones distintas; respecto de la segunda, desde el desplazamiento del menor son tres años los que el progenitor tarda en actuar y solicitar la restitución del menor. El consentimiento, aunque en este caso parece ser implícito, su prueba demuestra su existencia de forma efectiva e incuestionable.

\section{La interpretación del consentimiento al traslado por la AP de Barcelona en el auto de 27 de noviembre de 2018}

27. El consentimiento al traslado del menor es una cuestión de prueba y como tal es quien alega su existencia quien tiene que probarlo. En el marco del litigio tanto la AP como el juez de Primera

\footnotetext{
29 JUR/2003/197519

${ }^{30}$ En su F ${ }^{\mathrm{o}} \mathrm{J}^{\mathrm{o}}$ Segundo.

31 JUR/2012/289697.

${ }^{32} \mathrm{~F}^{\mathrm{o}} \mathrm{J}^{\mathrm{o}}$ Primero.

${ }^{33}$ En el supuesto se solicitó ante el Tribunal español la adopción de medidas de protección por el progenitor quien consideraba que la residencia habitual del menor estaba situada en territorio español y por tanto resultaba aplicable el artículo 8 del R. 2201/2003. El menor había sido trasladado por la progenitora a Ecuador. Auto núm. 135/2017 ECLI:ECLI:ES:APGR:2017:1186A
} 
Instancia entendieron que la retención del menor en España era lícita, por tanto, quien alegó tal consentimiento fue quien tuvo que demostrarlo.

28. La Audiencia considera que el consentimiento del progenitor se produce en tres momentos distintos: primero en el traslado del menor a España; segundo durante la estancia en España; por último, en tercer lugar, en la permanencia definitiva del menor en España.

Para cada uno de ellos la progenitora, que alega la existencia del consentimiento del progenitor, y por tanto la aplicación de la excepción al retorno del artículo 13 a) del CLH de 1980, basa su existencia en las siguientes pruebas: en relación al consentimiento del traslado, el hecho de que el progenitor llevó a la madre y al hijo al aeropuerto donde cogerían el vuelo a España (marzo 2017); en relación al consentimiento durante la estancia en España, el progenitor visita a la madre y al hijo cinco meses más tarde del desplazamiento a España, y en ningún momento se opone a la permanencia del menor en España (julio 2017); en cuanto a la permanencia definitiva del menor junto a la madre en España, y tras expresar la madre al progenitor su firme decisión de quedarse en España con el menor, el padre se ofrece enviar la documentación necesaria para que la madre se dirija a la Embajada de Corea en España, y textualmente la comunica que: “(...) facilitará lo necesario para inscribir al menor (...)” (septiembre 2017).

29. La excepción del artículo 13 a) del CLH de 1980 solo se refiere al comportamiento de quien inicia el proceso de restitución y, por tanto, sostiene la ilicitud del traslado o permanencia del menor, pero ¿tiene alguna incidencia el comportamiento o actitud de quien desplazada al menor si en principio y durante un tiempo de su estancia muestra intención de volver al Estado donde permanece el otro progenitor, y sin embargo finalmente decide permanecer en el segundo Estado? Sobre este elemento, la Audiencia en su decisión se refiere a que la progenitora no mostró de manera firme su decisión de permanecer en España hasta septiembre de $2017^{34} \mathrm{y}$, en consecuencia, en ningún momento durante el tiempo que estuvo en España manifestó su intención de no retornar a Corea; ahora bien, este comportamiento -reconocido por la progenitora durante el proceso- no es un aspecto que posteriormente incida en la decisión del Tribunal ${ }^{35}$. La AP basa su decisión, siguiendo lo previsto en el artículo 13 letra a) del CLH de 1980, únicamente en el comportamiento que el otro progenitor tiene en torno a su consentimiento.

30. Pues bien la Audiencia determina: "Se acredita pues, el consentimiento paterno tanto en un momento inicial de traslado del hijo común con la madre en marzo 2017 a España, como a la permanencia del menor en julio 2017 en este país, así como la facilitación de documentación necesaria para que el menor permanezca en España con la madre, sin que en ningún momento el padre objetara que tal documentación se proporcionaría para un tiempo limitado y determinado, con lo que no está mostrando el hoy recurrente una oposición clara y rotunda a la permanencia del menor en este país".

31. De la valoración realizada por el juzgador, y teniendo en cuenta que el consentimiento al desplazamiento es una cuestión de prueba, parece deducirse que solo un comportamiento claro y firme por quien se opone a la permanencia del menor en el Estado al que ha sido trasladado contrarresta los elementos de prueba en los que se apoya quien alega dicho consentimiento. Además, conforme a la lectura de la Sentencia, para que no haya duda de la falta de consentimiento el comportamiento en este sentido, del progenitor que alega no haberlo dado, ha de ser continuado en el tiempo.

\footnotetext{
${ }^{34} \mathrm{~F}^{\mathbf{0}} \mathrm{J}^{\mathrm{o}}$ Tercero.

${ }^{35}$ Sí parce que en el asunto resuelto por el Auto de la AP de Las Palmas (Sección 3 ${ }^{a}$ ) de 21 de junio de 2017, el Tribunal tiene más en cuenta la actitud del otro progenitor. En dicha decisión el Tribunal establece: "Que no existió un verdadero consentimiento se demuestra por varios datos, como el que en la entrevista con los servicios sociales del Ayuntamiento, en marzo de 2016, el padre de José Daniel manifestaba que pensaba trasladarse a Londres para tramitar el cambio de custodia y residencia, lo que demuestra su conocimiento de la situación irregular de la estancia de su hijo en Las Palmas. Lo cual vuelve a reiterar en manifestaciones posteriores, donde incluso reconoce que no puede viajar con su hijo porque la madre le niega ya el permiso de viaje para el niño (informes del Ayuntamiento unidos como prueba documental de la demanda)”. $\mathrm{F}^{\mathrm{o}} \mathrm{J}^{\mathrm{o}}$ Tercero.
} 


\section{A modo de conclusión}

32. La decisión adoptada por la AP de Barcelona pone de manifiesto varios aspectos:

En primer lugar, el supuesto que resuelve es un ejemplo de las situaciones conflictivas que las crisis familiares internacionales suscitan cada vez en mayor número.

En segundo lugar, la importancia de la existencia de textos internacionales que solventen las cuestiones jurídicas que se plantean, y que dichos instrumentos sean ratificados por el mayor número de Estados.

En tercer lugar, y es el elemento central del asunto, en una situación de desplazamiento o retención de un menor en un segundo Estado las excepciones a su restitución tienen que tener una aplicación limitada.

En cuarto lugar, en un supuesto como el resuelto por la AP de Barcelona en el que se alega la licitud de la retención del menor en España por el consentimiento del otro progenitor la prueba de su existencia recae en quien lo alega como excepción al retorno. En ningún momento hay referencia al modo en el que el consentimiento al traslado ha de otorgarse: de forma expresa o ser implícito.

La excepción al retorno recogida en el artículo 13 letra a) del CLH de 1980 es de perfiles muy dudosos de ahí la importancia de tener sólidos elementos de prueba que confirmen el consentimiento al traslado. Elementos que han de demostrar: que el consentimiento no tenía un alcance temporal limitado, y que existe consciencia de la vinculación que el traslado consentido del menor supondrá jurídicamente, por ejemplo, en torno al cambio legal de residencia y con ello la modificación en la competencia de las autoridades. En definitiva, se ha de probar de forma clara y convincente que el consentimiento tuvo lugar. De manera que, la decisión de quien alega ahora no haber otorgado el consentimiento es resultado de su arrepentimiento circunstancia que no transformará el traslado o retención de lícito en ilícito. 